this is certainly an important result. In view of this it seems very unfortunate that Prof. Gatenby has stated that, apart from Dr. Bowen's new interpretation of the sperm tail, " he adds nothing new to our knowledge of the spermatogenesis of the Lepidoptera." He considers the value of Dr. Bowen's work to lie in the fact that it confirms his own drawings of the appearance of the mitosome. After carefully comparing Dr. Bowen's paper with the original paper by Prof. Gatenby (Q.J.M.S., 62, p. 407) I really cannot agree that there is any confirmation whatever. One figure by Dr. Bowen (Fig. 43) superficially resembles a corresponding one in Prof. Gatenby's paper (Fig. I4). Otherwise the figures of the mitosome are totally different in the two papers.

Prof. Gatenby has not:answered the criticism that I have made of his original description of the formation of the mitosome. I cannot see how the chromophilic outer surface of a drop-which, of course, has an appreciable area - can, by fusion with another drop, or even by mere elongation, become transformed into a thread-like loop that has no appreciable area. He states merely that the mitochondrial vesicles flow together, " forming, at first, elongated structures, then loops, and finally filaments." I have pointed out (Q.J.M.S., 66, p. 665) that I consider the figures that accompany this description inaccurate and misleading. Further, if such a process does take place, surely it would be possible to observe the intermediate stages, and would not these, in any case, be some sort of plate work? If Prof. Gatenby would enlarge upon his somewhat brief description it might help to clear up the differences between our views.

With regard to the opinion of the late Prof. Doncaster on the formation of the mitosome I should like to add a few remarks. In Igrg I had the privilege of assisting Prof. Doncaster in working out the spermatogenesis of the louse Pediculus corporis. We divided the work into two, he dealing chiefly with the chromosome aspect, while I dealt mainly with the cytoplasmic inclusions. At first Prof. Doncaster was inclined to believe that the mitosome was formed in the manner described by Prof. Gatenby, and, in fact, in the original notes, which I now possess, there are rough drawings by Prof. Doncaster figuring the mitosome as a spireme. I could not accept this view, and explained my conception to him. Ultimately he agreed with me, and it was at this time-about May or Junethat he paid the visit to Prof. Gatenby, and objected to the latter's description of the mitosome of Smerinthus. However, that he was quite prepared to accept Prof. Gatenby's description is shown by the fact that in his last book on cytology he gives Prof. Gatenby's account in full and does not, I think, refer to our own observations on Pediculus.

Zoology Department,

Imperial College of Science,

South Kensington.

\section{The Rodier System of Rat Repression.}

IN connexion with the article on "The Rat and its Repression," contributed by me to NATURE of May 20, I922 (vol. I09, p. 659), I have been favoured with a letter from Mr. Wm. Rodier of Melbourne in which he complains that my attitude to his system of rat repression is unsympathetic, or that, conversely, he is misunderstood.

I should esteem it a favour if you would allow me to say that I am not unsympathetic to any means of destroying the rat-an animal which $\mathrm{I}$, at least, consider to be one of the greatest menaces of modern civilisation.

The attitude I take to the "Rodier Method" of rat destruction is that its principles are so thoroughly understood by all who have studied the rat problem that I am conscious of no unfairness when I suggest Mr. Rodier harms his cause when he asserts that those who do not immediately and unreservedly become his disciples are necessarily antagonistic, or stupid.

The difficulties Mr. Rodier has to overcome are such as are presented by the attitude of authorities towards putting rats back by rat-catchers who are paid to destroy their catches; the attitude of business houses when they pay for rat-clearing and find male rats turned back; and the plight of boroughs who make it their business to destroy female rats, when they find their polygamous males mated by females from contiguous boroughs where the " Rodier Method" is not in operation.

The whole question is one of education, and my immediate object is to convince the public that the rat is one of man's most dangerous foes; and one that is too expensive to maintain. As for the Rodier method, I have an open and sympathetic mind; and I would suggest that it would help Mr. Rodier's propaganda enormously if he could show us good results that could be scientifically checked, say in an island like Tristan da Cunha, or the Isle of Man. The authorities in the former island, where I am assured rats climb trees, would doubtless welcome assistance to overcome their terrible foes.

Alfred E. MOORE.

The Incorporated Vermin Repression Society, 44 Bedford Row, London, W.C.I,

$$
\text { April } 28 .
$$

\section{Active Hydrogen by Electrolysis.}

IN 1907 Fischer and Massenez (Z. anorg. Chem., $52,202,1907)$ obtained a concentration of 17 per cent. by weight of ozone when they electrolysed a solution of sulphuric acid, using a very high current density. Since ozone can be produced by this method, it would seem probable that a high current density at the cathode might aid in producing the ozone form of hydrogen. When a solution of sulphuric acid is electrolysed, using the above principle, the hydrogen that escapes at the cathode contains an active constituent which combines with pure nitrogen to form ammonia. Some of the ammonia formed is collected in the absorption bulb, but quite a large portion of it remains dissolved in the sulphuric acid solution. This active constituent in the hydrogen that is evolved at the cathode is probably the ozone form, and is produced perhaps in a manner analogous to the ozone form of oxygen. The per cent. of the active gas formed varies with the current density and the concentration of the acid.

Likewise, if a solution of potassium hydroxide is electrolysed, using a high cathode current density, the escaping hydrogen contains the ozone form which combines with pure nitrogen to form ammonia.

In the electrolysis of the acid solution the escaping hydrogen contains a fog which persists after passing through the absorbing solution. This fog is similar to, but less dense than, the fog sometimes produced by ozone when it is bubbled through potassium iodide solution.

This work is a further verification of the theory of Dr. G. L. Wendt that tri-atomic hydrogen may be produced wherever atomic hydrogen is formed.

\section{Dept. of Chemistry,} A. C. GRubB.

University of Saskatchewan,

Saskatoon, Sask., Canada, April $\mathrm{x} 8$.

No. 2794 , VOI. I I I ] 